\title{
Assessing the perceived changes in neighborhood physical and social environments and how they are associated with Chinese internal migrants' mental health
}

\author{
Min Yang ${ }^{1 *}$, Julian Hagenauer ${ }^{1}$, Martin Dijst ${ }^{2,3}$ and Marco Helbich ${ }^{1}$
}

\begin{abstract}
Background: Migrants experience substantial changes in their neighborhood physical and social environments along their migration journeys, but little is known about how perceived changes in their neighborhood environment pre- and post-migration correlate with their mental health. Our aim was to examine the associations between recalled changes in the perceived neighborhood physical and social environments and migrants' mental health in the host city.

Methods: We used cross-sectional data on 591 migrants in Shenzhen, China. We assessed their risk of mental illness using the General Health Questionnaire (GHQ). Neighborhood perceptions were collected retrospectively pre- and post-migration. We used random forests to analyze possibly non-linear associations between GHQ scores and changes in the neighborhood environment, variable importance, and for exploratory analysis of variable interactions.

Results: Perceived changes in neighborhood aesthetics, safety, and green space were non-linearly associated with migrants' mental health: A decline in these characteristics was associated with poor mental health, while improvements in them were unrelated to mental health benefits. Variable importance showed that change in safety was the most influential neighborhood characteristic, although individual-level characteristics—such as self-reported physical health, personal income, and hukou (i.e., the Chinese household registration system)—appeared to be more important to explain GHQ scores and also strongly interacted with other variables. For physical health, we found different associations between changes in the neighborhood provoked by migration and mental health.
\end{abstract}

\footnotetext{
* Correspondence: yangminjamie@gmail.com

'Department of Human Geography and Spatial Planning, Faculty of

Geosciences, Utrecht University, Princetonlaan 8A, Utrecht, CB 3584, The Netherlands

Full list of author information is available at the end of the article
}

(c) The Author(s). 2021 Open Access This article is licensed under a Creative Commons Attribution 4.0 International License, which permits use, sharing, adaptation, distribution and reproduction in any medium or format, as long as you give appropriate credit to the original author(s) and the source, provide a link to the Creative Commons licence, and indicate if changes were made. The images or other third party material in this article are included in the article's Creative Commons licence, unless indicated otherwise in a credit line to the material. If material is not included in the article's Creative Commons licence and your intended use is not permitted by statutory regulation or exceeds the permitted use, you will need to obtain permission directly from the copyright holder. To view a copy of this licence, visit http://creativecommons.org/licenses/by/4.0/. The Creative Commons Public Domain Dedication waiver (http://creativecommons.org/publicdomain/zero/1.0/) applies to the data made available in this article, unless otherwise stated in a credit line to the data. 
Conclusion: Our findings suggest that perceived degradations in the physical environment are related to poorer post-migration mental health. In addition, it seems that perceived changes in the neighborhood environment play a minor role compared to individual-level characteristics, in particular migrants' physical health condition. Replication of our findings in longitudinal settings is needed to exclude reverse causality.

Keywords: Migrants, Neighborhood changes, Moving trajectory, Relocation, Mental health, Machine learning

\section{Background}

Between 1979 and 2019, China's urban population increased from 17 to $60 \%$ [1]. The country's annual economic burden caused by mental disorders quadrupled from $\$ 21.0$ billion to $\$ 88.8$ billion between 2005 and 2013 [2]. Internal migrants contributed significantly to China's growing urban population, and they are particularly vulnerable to mental illness resulting from changes in their social and physical living environments [3-5].

Evidence is mounting that risk factors for mental illness in host cities are different for migrants compared to non-migrants; for example, migrants tend to have a low socioeconomic status, are separated from their families, and are socially excluded from their host societies [6-9]. Furthermore, hukou (i.e., the Chinese household registration system) prevents migrants from accessing social and medical benefits in host cities. Failure to transfer their hukous to host cities puts migrants at additional mental health risk because of the associated social welfare and healthcare inequalities [10].

Studies have shown that good neighborhood physical and social environments contribute to mental health among the general population [11]; in this, the social environment seems to play a more important role [12]. For example, noise [13], air pollution [14], lack of essential neighborhood facilities (e.g., lighting, benches) [15], and safety concerns [16] were found to threaten mental health. In contrast, neighborhood social cohesion and social support [17] may contribute to better mental health. The physical environment in the form of green space may also promote mental health [18].

Previous studies on neighborhood-mental health relationships were limited in two ways. First, it remains unclear whether such associations hold for migrants experiencing changes in their living environment due to moving. This concern echoes criticism put forward elsewhere [19] that neighborhood environments are measured at a single point in time [20-22], which may lead to over-emphasizing the role of the neighborhood in which people currently live. Only a few studies have incorporated neighborhood experiences at multiple stages of people's lives [23-25]. It is plausible that migrants' mental health is shaped by both the previous and the actual neighborhood environment [19, 26, 27]. For example, a US study showed that moving away from an impoverished neighborhood resulted in improved mental health [28].

Second, some studies (i.e., [29-31]) have a methodological deficit because they were mainly based on inflexible regression analyses assuming that neighborhoodmental health correlations are linear. While there is no plausible reason for such a simplification, this may at least partly contribute to inconsistent results across studies [32]. To overcome these constraints, others have promoted the application of more flexible machine learning approaches to uncover complex and possibly non-linear associations [12]. Non-linearities make intuitive sense, because people's mental health might not respond in the same way to an improvement or deterioration of the neighborhood environment. Meanwhile, several machine learning models (e.g., random forests) have demonstrated their analytical advantages by routinely assessing the importance of explanatory variables and modeling variable interactions [33], which supports our understanding concerning the mechanisms underlying how neighborhood characteristics correlate with mental health.

To address these limitations, the present study used random forests to examine associations between the perceived changes in neighborhood physical and social environments pre- and post-migration and migrants' mental health in the host city of Shenzhen, China. Three research questions were formulated:

1) How are recalled changes in perceived neighborhood characteristics associated with migrants' mental health in the host city?

2) Which perceived neighborhood changes are most influential for migrants' mental health?

3) How do migrants' individual-level characteristics interact with neighborhood-level characteristics in associations with current mental health?

\section{Materials and methods}

\section{Study area and study design}

A cross-sectional observational study was conducted in the city of Shenzhen, China. Shenzhen has a population of 11.37 million people, $70 \%$ of whom are migrants [34], which made it an ideal site for our study.

Data were collected by means of a survey carried out between January and April 2017. We selected participants using a stratified sampling design. First, two inner- 
city districts (Nanshan and Futian) and two suburban districts (Longgang and Baoan) were chosen as sampling areas. Second, within each of the districts, five neighborhood types were identified based on the neighborhood physical environment and the socioeconomic composition of the residents. These neighborhood types can be broadly defined as work unit compound, inner-city village, commodity housing community (a private real estate development), social housing, and factory dormitory. Previous research stressed the differences in socioeconomic composition and physical environment between different neighborhood types [35]. Finally, we took a random sample of people per selected neighborhood. Eligible to participate were people older than 18 years who had lived in Shenzhen for at least 6 months. In total, our sample included 855 respondents. After removing non-migrants (i.e., people born in Shenzhen, $N=264$ ), the final sample comprised 591 people.

\section{Data}

\section{Mental health as outcome variable}

Migrant's self-reported mental health was assessed using the well-tested Chinese version [36] of the 12-item General Health Questionnaire (GHQ-12) [37]. The GHQ-12 is a psychometric screener dealing with people's emotions and daily functioning in the 4 weeks prior to the survey. The items address respondents' experience of self-confidence, losing sleep, and other psychiatric conditions. Each item was scored on a 4-point Likert scale ranging from 0 (not at all) to 3 (yes, always). The 12 individual scores were summed, leading to a total score that served as our outcome variable. The GHQ-12 in our sample ranged from 0 (good mental health) to 30 (poor mental health). A Cronbach's alpha of 0.821 indicated the good internal consistency of the GHQ-12 in our sample.

\section{Perceptions of the residential neighborhood pre- and post- migration}

We assessed the physical and the social dimension of migrants' residential neighborhoods pre- and postmigration. Although longitudinal data are preferred to measure neighborhood perceptions, our retrospective approach captures migrants' neighborhood experiences with minor recall bias [38, 39].

The neighborhoods' physical characteristics were measured by means of the short version of the Neighborhood Environment Walkability Scale (NEWS-A) [40]. We used 13 of the 54 NEWS-A items to represent neighborhood facilities and their accessibility (4 items), aesthetics ( 4 items), safety (2 items), and the availability of green space (3 items). Respondents were asked to assess their neighborhoods by means of a 5-point Likert scale. The items for each attribute were then summed, with higher scores indicating better perceived neighborhood characteristics.

The neighborhood social environment was assessed by social cohesion, which was operationalized by asking respondents to rate the following statements on a 5-point Likert scale ranging from 1 (totally disagree) to 5 (totally agree): "People in the neighborhood are willing to help their neighbors", "The neighborhood organization is very helpful", "People in the neighborhood share the same values", "The neighborhood is close-knit", "People in the neighborhood can be trusted" [41]. The scores were summed, with higher scores indicating better perceived neighborhood social environments.

Changes in the perceived neighborhood environment were operationalized by subtracting the scores of the previous neighborhood from those of the current neighborhood. Values below 0 indicate a decline in a specific neighborhood attribute post-migration, while values above 0 indicate an improvement.

\section{Individual-level variables}

Following previous studies [10, 42] the following personal characteristics were included: age (measured in years), sex (male, female), education (high school or lower, bachelor's degree, master's or higher degree), personal monthly income (in $\mathrm{CNY} /$ month $[1 \mathrm{CNY}=0.14$ USD]), employment status (employed, unemployed), hukou type (a dummy variable referring to holding or not holding a Shenzhen hukou), and a variable representing the migration context (intra- or inter-province migration). We also considered self-rated physical health, as earlier studies suggested a relation between physical and mental health $[10,43]$. Physical health was measured on a 5-point scale from poor to excellent [44].

\section{Machine learning-based analyses}

Summary statistics were used to describe the study population. While there are numerous machine learning algorithms, studies have shown that random forests are competitive in their performance compared to other state-of-the-art machine learning models [12, 45]. For example, a competition of 38 algorithms concluded that the random forest model [33] has an outstanding predictive performance on a moderately large dataset and is a good initial algorithm choice [46].

We applied a random forest model [33, 47] to assess the associations between GHQ-12 scores and environmental changes between migrants' previous and current neighborhoods. A random forest has the advantage that it models non-linear associations, includes interactions between variables, is not grounded on statistical assumptions, and is robust against overfitting [48]. Briefly, a random forest is a regression method that consists of a large number of different trees (i.e., an ensemble of 
trees) [33]. Each tree is built based on a bootstrap sample (i.e., sampling with replacement) of the data. When growing an individual tree, at each node only a random subset of the independent variables is selected which reduces the correlations among the trees. Finally, trees are grown to maximum size without any pruning and the overall predictions of the random forest are obtained by averaging the predictions from the individual regression trees.

Four approaches were used to obtain an in-depth model understanding. First, we assessed the variable importance by measuring how much, on average, each variable decreases the variance when the trees are grown (see, e.g., [49] for details). Second, we used partial dependence plots-which show the change in the average predicted value as one or more variables vary over their marginal distribution [50] - to investigate the directions and shape of the associations. Third, we quantified the total interaction of one variable with the other variables by means of the $\mathrm{H}$ statistic [51]. The statistic measures the variance of the difference between the observed partial dependence function and the decomposed one without interactions [52]. It can be calculated to evaluate the interaction of two variables or the overall interaction of one variable with all other variables. Values close to zero indicate no variable interactions, while values close to 1 indicate that the entire variance is explained by the partial dependence functions. Fourth, we visualized the interactions of selected variables (i.e., those having a high $\mathrm{H}$ statistic) using bivariate partial dependence plots. The analyses were carried out in $\mathrm{R}$ software [53] using the ranger package [54].

\section{Results}

Descriptive statistics

Table 1 presents the descriptive statistics of the study population. Our sample had a mean $(\mu)$ GHQ-12 score of 6.610 with a standard deviation (SD) of \pm 4.070 . The

Table 1 Descriptive statistics of the study population

\begin{tabular}{|c|c|c|c|c|c|c|}
\hline Variable & Category & Minimum & Maximum & Mean & SD & Percentage \\
\hline GHQ-12 scores & & 0.000 & 30.000 & 6.613 & 4.070 & \\
\hline \multicolumn{7}{|c|}{ Changes in neighborhood characteristics } \\
\hline Aesthetics & & -16.000 & 20.000 & -0.132 & 4.073 & \\
\hline Safety & & -8.000 & 8.000 & -0.029 & 1.855 & \\
\hline Facilities and accessibility & & -16.000 & 16.000 & 0.174 & 3.986 & \\
\hline Green space & & -12.000 & 12.000 & 0.240 & 3.092 & \\
\hline Social cohesion & & -20.000 & 20.000 & -0.052 & 4.681 & \\
\hline \multicolumn{7}{|l|}{ Individual-level characteristics } \\
\hline Age & & 17.000 & 68.000 & 31.374 & 7.911 & \\
\hline \multirow[t]{4}{*}{ Physical health } & Fair/poor & & & & & $35 \%$ \\
\hline & Good & & & & & $31 \%$ \\
\hline & Very good & & & & & $22 \%$ \\
\hline & Excellent & & & & & $13 \%$ \\
\hline \multirow[t]{2}{*}{ Hukou type } & Non-Shenzhen & & & & & $69 \%$ \\
\hline & Shenzhen & & & & & $31 \%$ \\
\hline \multirow[t]{2}{*}{ Migration context } & Intra-province & & & & & $32 \%$ \\
\hline & Inter-province & & & & & $68 \%$ \\
\hline \multirow[t]{2}{*}{ Sex } & Female & & & & & $44 \%$ \\
\hline & Male & & & & & $56 \%$ \\
\hline \multirow[t]{3}{*}{ Education } & High school or lower & & & & & $32 \%$ \\
\hline & Bachelor's & & & & & $62 \%$ \\
\hline & Master's and higher & & & & & $6 \%$ \\
\hline \multirow[t]{3}{*}{ Income } & $\leq 4000 \mathrm{CNY}$ & & & & & $23 \%$ \\
\hline & 4001-8000 CNY & & & & & $43 \%$ \\
\hline & $>8000 \mathrm{CNY}$ & & & & & $34 \%$ \\
\hline \multirow[t]{2}{*}{ Employment } & Unemployed & & & & & $23 \%$ \\
\hline & Employed & & & & & $77 \%$ \\
\hline
\end{tabular}


average age of our respondents was 31.374 years $(\mathrm{SD} \pm$ 7.911 ) and $44 \%$ were female. Both age and sex distributions of our sample matched closely the demographic profile of people in Shenzhen in 2018, when the mean age of the permanent residents was 32.5 years and $46 \%$ of the permanent residents were female (Statistics Bureau of Shenzhen Municipality, 2019). Because only a few respondents reported "poor" physical health, we merged the "poor" and the "fair" group into a "fair/poor" group, which accounted for $35 \%$ of the sample. Well over half (66\%) of the respondents had at least good physical health. Over two thirds (69\%) of the respondents were currently living in Shenzhen without a Shenzhen hukou, and $68 \%$ of these respondents had migrated from places outside the province (e.g., Guangdong). The average length of residence in Shenzhen was 4.350 years (SD \pm 4.398). Approximately 34\% of respondents lived in Shenzhen for 1 year or less.

Table 2 shows the changes in the perceived neighborhood environment pre- and post-migration. Approximately one third of the respondents reported improvements in the neighborhood environment, one third remained stable, and one third experienced a decline after moving to Shenzhen. The perceived changes in neighborhood conditions showed that, on average, the respondents experienced a slight decline in neighborhood quality post-migration in terms of aesthetics $\mu=-0.132$, $\mathrm{SD} \pm 4.070)$, safety $(\mu=-0.029, \mathrm{SD} \pm 1.866)$, and social cohesion $(\mu=-0.052, \mathrm{SD} \pm 4.681)$. The neighborhood facilities and accessibility $(\mu=0.174, \mathrm{SD} \pm 3.986)$ and green space $(\mu=0.240, \mathrm{SD} \pm 3.092)$ improved post-migration.

\section{Variable importance}

Figure 1 shows the variable importance for explaining migrants' GHQ-12 scores. Physical health, income, and age were found to be the most important variables correlating with GHQ-12, followed by migrants' hukou type and sex. Perceived changes in neighborhood characteristics were less important in explaining migrants' mental health in the host city. The most irrelevant variables were education and employment status.

\section{Correlation analysis}

Figure 2 shows the correlations between the GHQ-12 scores and the independent variables as partial dependence plots. A decrease in a migrant's perception of safety was associated with a higher GHQ-12 score (meaning poorer mental health), while an increase was not associated with a lower GHQ-12 score (meaning better mental health). A similar pattern was found for perceived changes in neighborhood green space and aesthetics, where a reduction in the experiences of green space and aesthetics were associated with higher GHQ12 scores. A decrease in GHQ-12 scores was observed for respondents with improvements (above 5) in green space. A decline in the perceived social cohesion postmigration was associated with higher GHQ-12 scores, and an increase with lower GHQ-12 scores.

As for individual-level characteristics, migrants with a Shenzhen hukou had lower GHQ-12 scores than those without a Shenzhen hukou. Inter-province migrants also had better mental health than intra-province migrants. Male migrants had higher GHQ-12 scores than female migrants. The overall trend indicated that better selfrated physical health was associated with lower GHQ-12 scores. There was a substantial drop in GHQ-12 scores between migrants who assessed their physical health as "fair/poor" and migrants who reported "very good" physical health. In contrast, the GHQ-12 difference between "very good" and "excellent" physical health was minor. A similar trend was found for income, whereby higher income levels were associated with lower GHQ-12 scores; the GHQ-12 score difference between the low- and the middle-income group was greater than that between the middle- and the high-income group.

\section{Variable interactions}

We further explored the variable interactions, Fig. 3 shows the $\mathrm{H}$ statistics for the variables used to evaluate variable interactions. Physical health, income, hukou type, and sex had pronounced overall interaction. The remaining variables, including all neighborhood characteristics, showed moderate to little interaction. To investigate the most important interactions among variables, we calculated bivariate partial dependence plots for those with high overall interaction (i.e., physical health, income, hukou type, and sex) (Fig. 4). Less substantial bi-variate interactions are provided in the supplementary materials.

Table 2 Changes in the perceived neighborhood environment pre- and post-migration

\begin{tabular}{llll}
\hline & Decline & Stable & Improvement \\
\hline Perceived changes in neighborhood aesthetics & $38 \%$ & $24 \%$ & $38 \%$ \\
Perceived changes in neighborhood safety & $33 \%$ & $38 \%$ & $29 \%$ \\
Perceived changes in facilities and accessibility & $35 \%$ & $30 \%$ & $35 \%$ \\
Perceived changes in neighborhood green space & $32 \%$ & $31 \%$ & $37 \%$ \\
Perceived changes in the neighborhood social environment & $36 \%$ & $26 \%$ & $38 \%$ \\
\hline
\end{tabular}




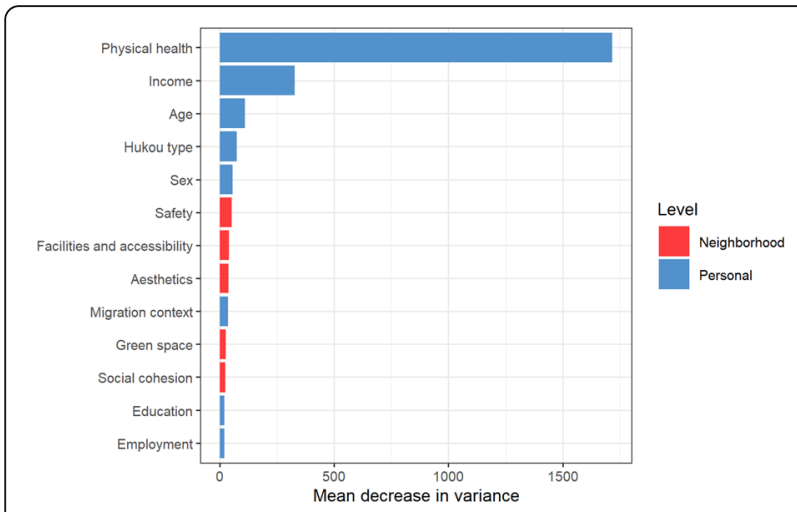

Fig. 1 Variable importance of the individual-level and neighborhood-level characteristics. The higher the mean decrease in variance, the more important the variable
The association between hukou type and GHQ-12 scores varied by the level of income, whereby migrants with a Shenzhen hukou scored lower on GHQ-12 than those with a non-Shenzhen hukou. The difference in GHQ-12 scores between hukou types was more noticeable for the middle- and high-income groups than for the low-income group. The relationship between hukou type and GHQ-12 also varied by physical health. Among those who rated their physical health as good, nonShenzhen hukou holders had higher GHQ-12 scores than hukou holders; there was little difference for other physical health levels.

The association between income level and GHQ-12 showed different patterns across physical health levels. A sharp drop in GHQ-12 scores between the low- and the middle-income group was found for migrants who rated their physical health as fair or poor. The pronounced
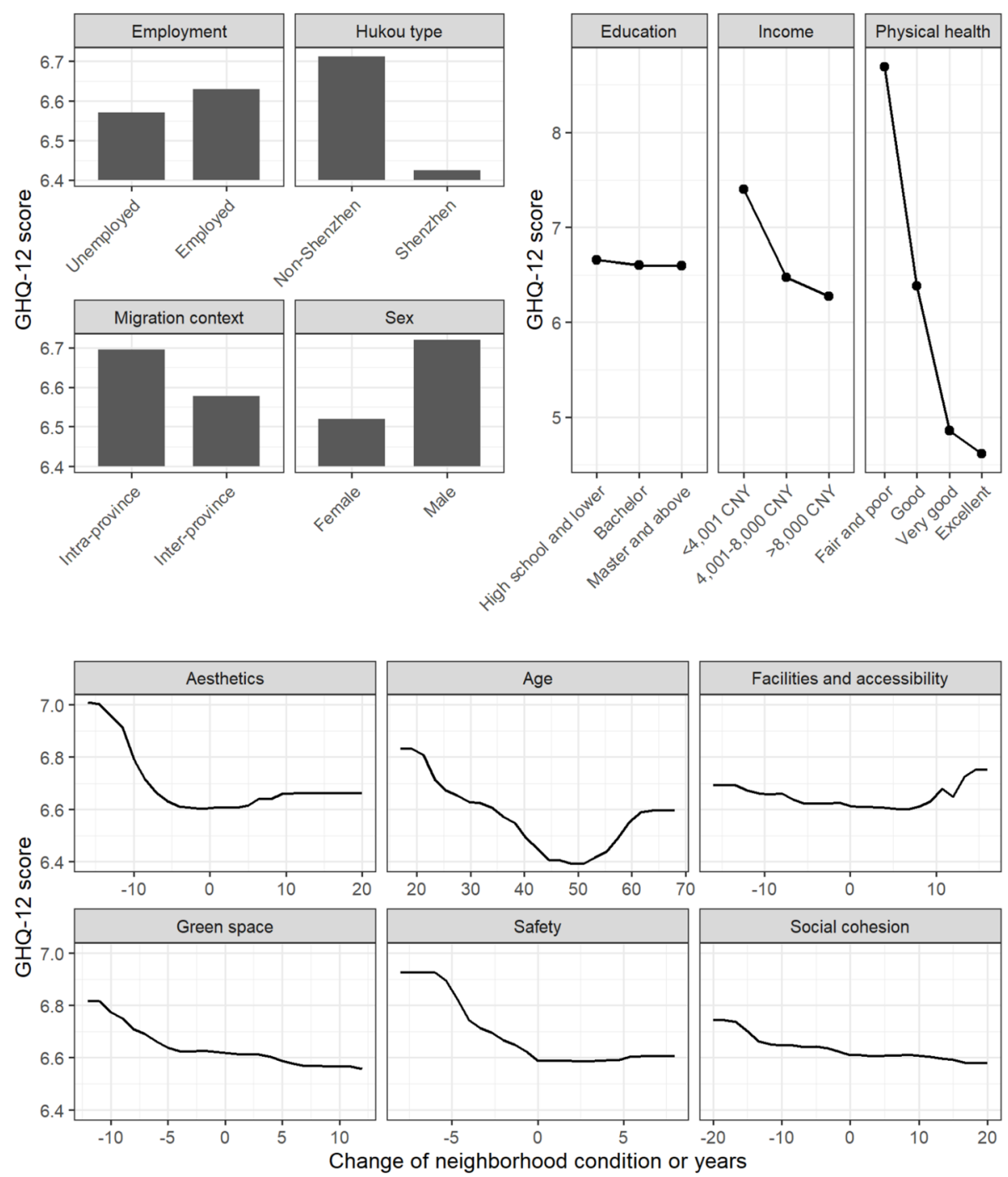

Fig. 2 Partial dependence plots relating each independent variable to the GHQ-12 scores 


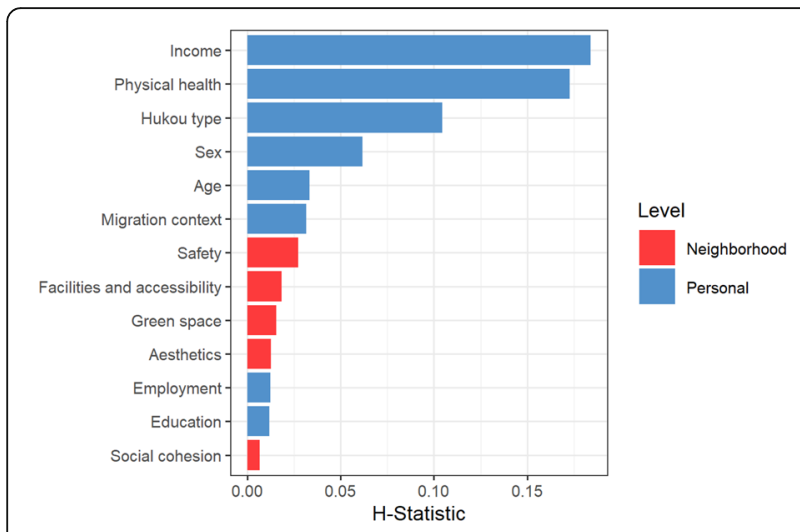

Fig. 3 Overall variable interactions of the individual-level and changes in neighborhood characteristics. The higher the H statistic, the stronger a variable's interaction with the other variables

negative association between income and GHQ-12 scores were flattened for migrants who rated their physical health as better than fair/poor.

Even though changes in neighborhood characteristics were not strongly related to migrants' GHQ-12 scores (Fig. 1), the associations varied across different physical health levels. Figure 5 shows the associations between changes in perceived neighborhood characteristics and GHQ-12 scores for migrants with different physical health levels. Respondents who rated their physical health as very good or excellent showed a sharper increase in GHQ-12 scores when they experienced a decline in neighborhood aesthetics and safety postmigration. A similar trend appeared between changes in perceived safety and GHQ-12 for migrants with good physical health. Yet, for migrants with fair/poor physical health, their GHQ-12 scores remained high regardless of whether changes in aesthetics and safety were experienced. In addition, we observed a sharp increase in GHQ-12 scores when migrants with very good or excellent physical health experienced a substantial improvement (above 10) in neighborhood facilities and accessibility. As for changes in green space and social cohesion, those who rated their physical health as fair/ poor showed a more pronounced negative association between neighborhood changes and GHQ-12 scores compared to other physical health groups.

\section{Discussion}

We conducted a machine learning-based analysis to examine the associations between perceived changes in multiple neighborhood physical and social environmental characteristics pre- and post-migration and migrants' mental health in Shenzhen, a metropolis whose population is largely composed of migrants. We also addressed

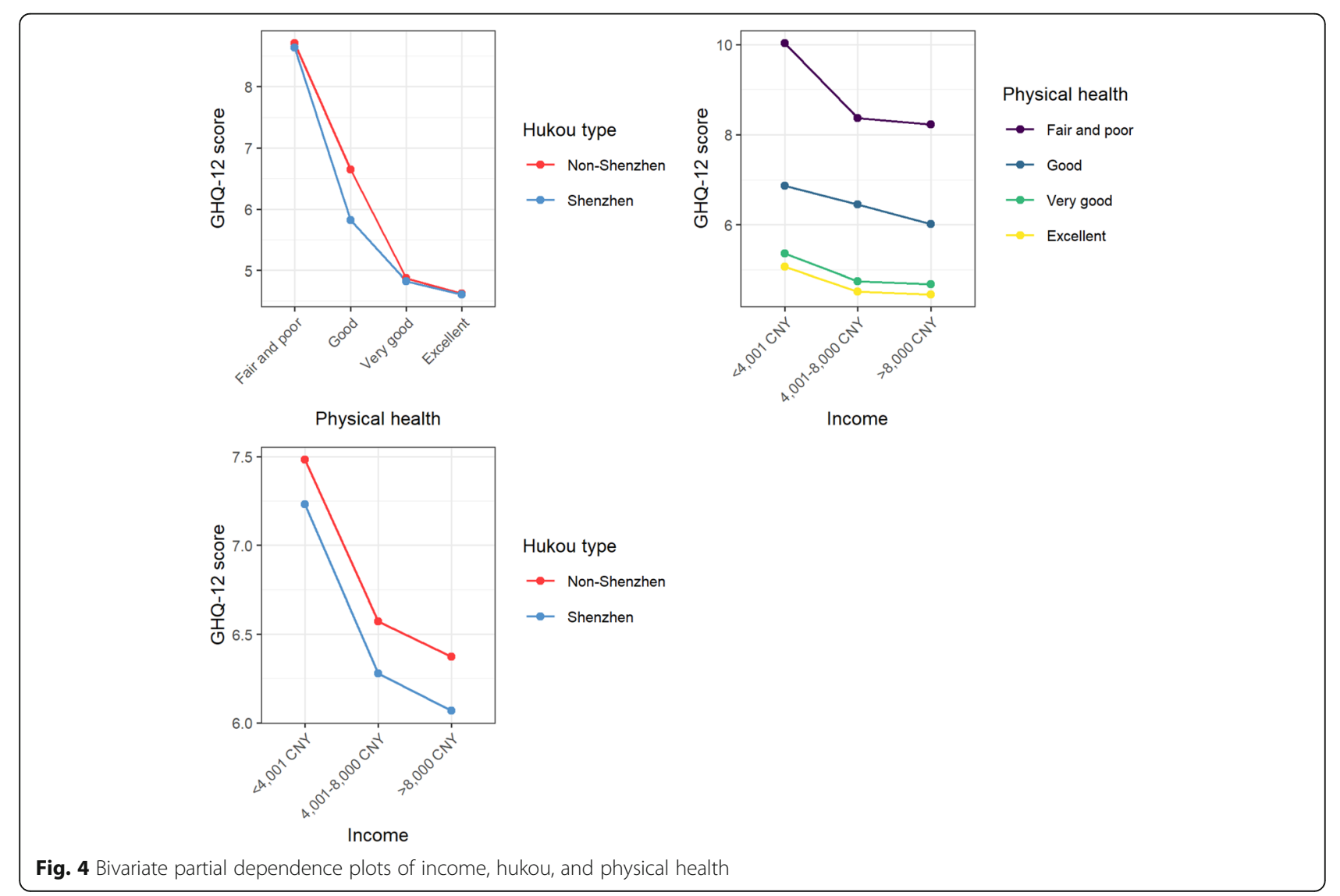



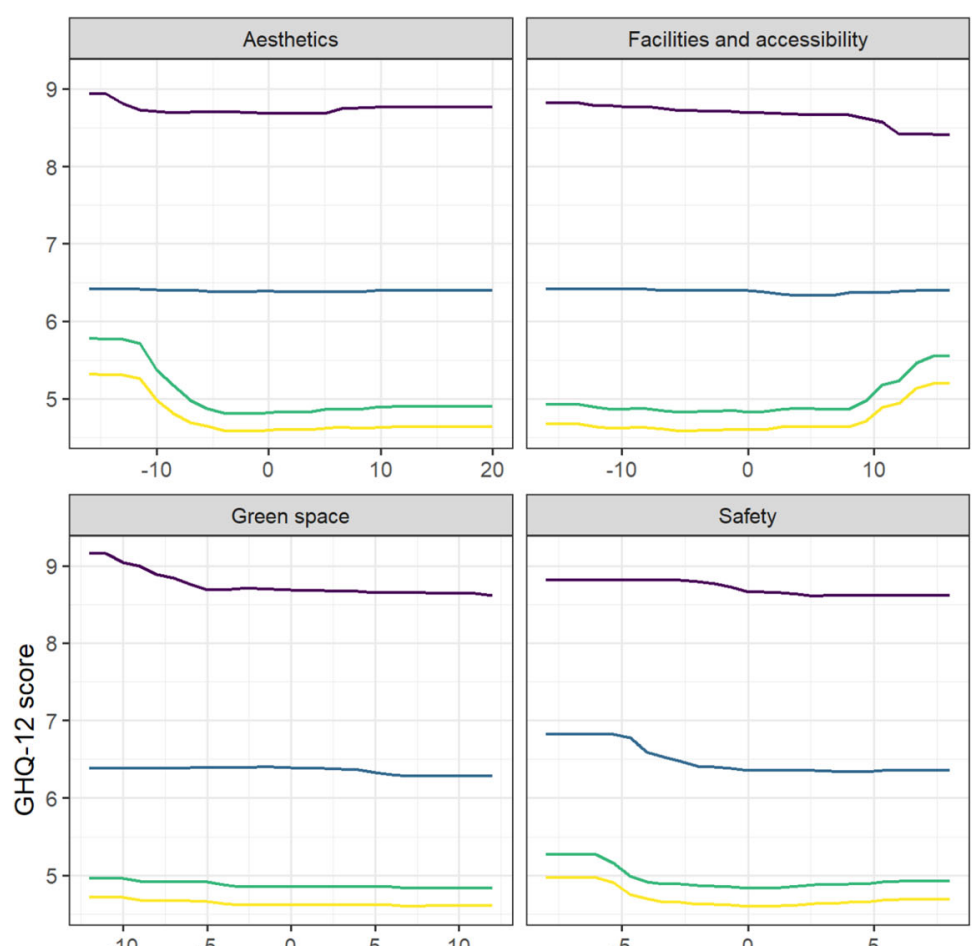

Physical health

- Fair and poor

- Good

- Very good

Excellent

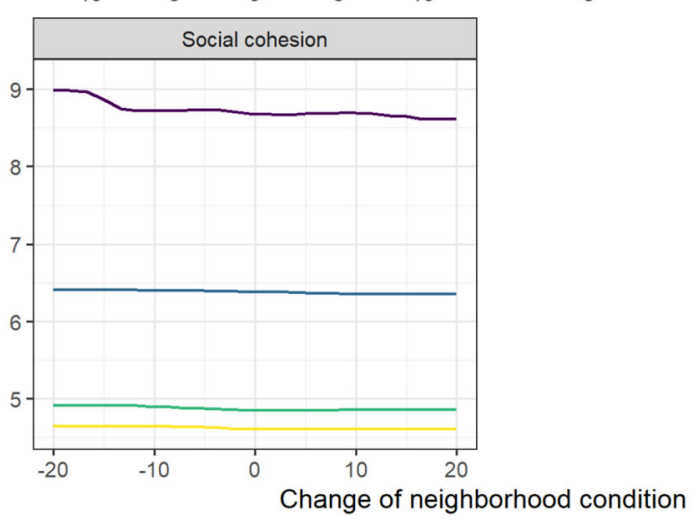

Fig. 5 Bivariate partial dependence plots of physical health and neighborhood characteristics

how important changes in neighborhood characteristics are related to individual-level characteristics in an exploratory manner, including their level of interactions across variables - an issue that has rarely been examined.

\section{Experience of environmental neighborhood change}

We found that, in general, migrants experienced a decline in perceived neighborhood aesthetics, safety, and social cohesion post-migration. This result supports studies that have reported that migrants are likely to end up in less desirable neighborhoods due to their disadvantaged position in the local housing market [55]. Unaffordable housing prices in Shenzhen [56], combined with a lack of family support, social capital, and financial capital, contributed to migrants' higher level of housing stress and poorer neighborhood choice in Shenzhen [57]. Meanwhile, migrants' social integration may negatively affect their perception of social aspects of the neighborhood environment [17], contributing to their reduced perceptions of neighborhood social cohesion in the host city.

In addition to the experienced decline in neighborhood aesthetics, safety, and social cohesion, our respondents also reported an improvement in neighborhood facilities and accessibility and in green space in Shenzhen. Since the majority of internal migration flows in China are rural to urban and/or from less developed cities to metropolitan areas [58], migrants may experience an overall improvement in urban infrastructure provision at their destination in Shenzhen. The increased green space perception in 
Shenzhen could be attributed to the city's subtropical climate, which makes it greener than most other Chinese cities, especially northern cities: In 2018, the green coverage rate of Shenzhen's built-up area was $45.1 \%$, making it a top-ranking ecological environment among Chinese cities [59].

\section{Neighborhood change and mental health}

Our results suggest that post-migration, migrants moved to neighborhoods perceived as less safe and had poorer mental health. However, an improvement in neighborhood safety was not associated with mental health benefits. Similarly, non-linear associations with mental health were also found for neighborhood aesthetic quality and green space, where only the association between a decline in neighborhood characteristics and poor mental health was identified. Empirical studies have suggested that neighborhood safety, aesthetic quality, and green space contribute to residents' mental health $[16,60,61]$. Therefore, it is reasonable to conclude that a decline in such neighborhood characteristics may contribute to mental illness. Furthermore, due to institutional barriers caused by hukou, and a lack of social support in the host city, migrants struggle to maintain their neighborhood quality in the host city [62], which may induce additional stress as a result of ending up in deprived neighborhoods, putting them at risk for mental illness [17].

For neighborhood social cohesion, we found that a perceived decline in such cohesion is associated with poor mental health, and that a perceived improvement is associated with better mental health. Previous research has shown positive effects of perceived neighborhood social cohesion in terms of improving residents' life satisfaction [63] and enhancing their social contact and support [64], which contribute to good mental health.

In contrast to prior studies $[60,65]$ we found that people who moved to neighborhoods with better facilities and accessibility post-migration reported poorer mental health. However, some studies did find an association, albeit an insignificant one, between mental health and access to neighborhood facilities and services [6668]. Similarly, a UK panel data-based study [69] on internal migrants found that moving to a less deprived physical environment was associated with poor mental health. In fact, most evidence on the health-promoting role of neighborhood facilities and accessibilities concerns residents' physical (rather than mental) health, which is promoted by encouraging physical activities and more active traveling modes, such as walking and cycling [70-72]. Considering the limited and mixed results linking neighborhood facilities and accessibilities to mental health, we speculate that while better neighborhood facilities and accessibility may indirectly contribute to residents' mental health by improving their physical health, there are potential stressors that may offset the effect. For instance, neighborhoods with better facilities and accessibility may attract more visitors, increasing the density and crowdedness of the neighborhood, which will have negative impacts on mental health [73]. In sum, our results suggest that neighborhood changes and mental health have a complex, non-linear relationship. The mechanisms behind the patterns require more indepth and context-specific investigations.

In line with an earlier study concerning the general population [12], the variable importance showed that, in general, neighborhood characteristics were less important in explaining migrants' mental health outcomes compared to their individual-level characteristics (e.g., physical health, income, and hukou). A reason for this could be that individual-level characteristics, such as income and hukou, may not only serve as influential factors for migrants' mental health [10, 74], but also enable or constrain people's selection of neighborhood types [75]. Among the perceived neighborhood characteristics, it turned out that neighborhood safety in the host city was essential. This result is congruent with earlier work that reported that safety in the living environment is related more strongly to migrants' reduced psychological stress level in the host city than any other neighborhood physical characteristic [76].

\section{The importance of physical health}

Physical health is often strongly related to migrants' mental health [77], as it is for general populations [10]. Poor physical health may limit people's physical activity [77], which increases the risk for mental illness [78]. In addition, in our models we found striking interactions between self-rated physical health and income, hukou, and three neighborhood characteristics (green space, aesthetics, and safety). For instance, people with poor physical health were at greater risk for mental illness if they had a low personal income compared to those with better physical health. Similarly, the relationships between changed neighborhood-level characteristics and mental health varied across physical health groups. Specifically, migrants with fair/poor physical health were more sensitive to a decrease in perceived neighborhood green space.

Our results also showed that poorer mental health was associated with worsening perceived neighborhood aesthetics and safety only for those with at least very good physical health. Such differences across physical health groups may be due to the fact that physical health status may influence people's perception of their neighborhood environment [79]. Physical health conditions were also found to be related to the way and frequency with which people interact with their neighborhood environment [80]. For example, physically healthier people tend to go 
out more frequently than less healthy people, and thus their mental health response could be more sensitive to a decline in neighborhood aesthetics and safety.

\section{Other individual-level characteristics}

Income and hukou type were also found to be important for migrants' mental health in the host city. Several studies have suggested an income-health gradient, whereby a high personal income is associated with better mental health [81, 82]. A positive association between income, life satisfaction, and mental health may be especially important for migrants, because they mainly move to cities to earn higher incomes [6]. In our study, hukou was also of central importance for migrants' mental health, as highlighted in other Chinese studies [3, 83]. Hukou is strongly related to social welfare, health services, and the provision of other public services [84]. The difference between local hukou and non-local hukou holders regarding health insurance and social welfare indicates great health inequality in cities like Shenzhen [85]. Migrants frequently suffer from such inequality due to difficulties in transferring their hukous to the host city [10].

\section{Strengths and limitations}

Our study had numerous strengths. First, we focused on neighborhood changes pre- and post-migration, something that has rarely been done. Second, we incorporated multiple neighborhood characteristics rather than focus on a single one. This approach took into account that different neighborhood characteristics are likely to covary and influence each other. Third, in order to be methodologically innovative, we employed a data-driven random forest to assess the variable importance of neighborhood characteristics and their interactions, while going beyond linear relations.

Our study also had a number of limitations. First, the cross-sectional nature of the research design did not allow for causal statements and reverse causality remains an issue. We cannot preclude that people with poor mental health tend to have a more negative perception of their residential neighborhood and that those people self-select into more deprived residential areas. Second, although the perceived neighborhood characteristics have been found to be more influential for mental health than objective measures [86], we cannot rule out that people's perceptions vary, so their retrospective neighborhood assessments might have been prone to recall bias, which can be potentially influenced by various factors such as respondents' sociodemographics and the length of residence in Shenzhen. Finally, due to a lack of data on migrants' mental health conditions prior to moving to Shenzhen, we were not able to realize longitudinal analyses. Given these limitations, we encourage future studies to employ longitudinal designs that incorporate both objective and perceived neighborhood characteristics, while measuring changes in mental health over time.

\section{Conclusions}

This study was among the first to examine recalled changes in the perceived physical and social residential environments on internal migrants' mental health. We found that perceived negative changes of neighborhood aesthetics, safety, green space, and social cohesion were associated with poor mental health in the post-migration stage for migrants in Shenzhen. Yet, the associations between neighborhood environment changes and migrants' mental health were minor. Three individual-level characteristics-namely physical health, income, and hukouwere among the most important factors associated with migrants' mental health. In addition, physical health interacted strongly with other variables (e.g., income and hukou) when correlating with mental health.

\section{Abbreviation}

GHQ-12: The 12-item General Health Questionnaire

\section{Supplementary Information}

The online version contains supplementary material available at https://doi. org/10.1186/s12889-021-11289-4.

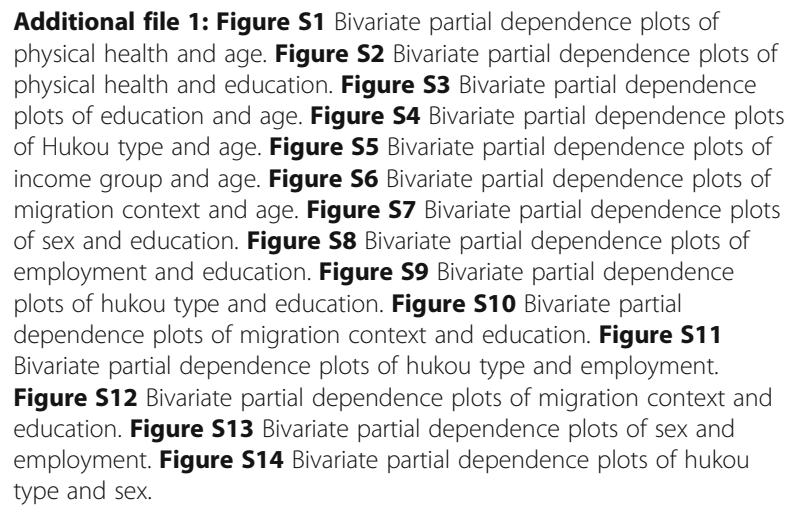

\section{Acknowledgements \\ The authors gratefully acknowledge the financial support from the Department of Human Geography and Spatial Planning of Utrecht University for data collection.}

\section{Conflict of interests}

The authors declare that the research was conducted in the absence of any commercial or financial relationships that could be construed as a potential conflict of interest.

\section{Authors' contributions}

Min Yang: Conceptualization, Formal analysis, Investigation, Data Curation, Writing - Original Draft, Funding acquisition. Julian Hagenauer: Methodology, Formal analysis, Writing - Review \& Editing. Martin Dijst: Writing - Review \& Editing, Supervision. Marco Helbich: Conceptualization, Methodology, Writing - Review \& Editing, Supervision. The author(s) read and approved the final manuscript. 


\section{Funding}

MY was supported by a grant from the Chinese Scholarship Council (CSC) (No. 201507720038). MH was funded by the European Research Council (ERC) under the European Union's Horizon 2020 research and innovation program (grant agreement No. 714993). In the course of the NEEDS project, JH's contribution was based on a research stay at Utrecht University. The CSC and ERC had no involvement in the study design, the writing of the manuscript, or the decision to submit the paper for publication.

\section{Availability of data and materials}

The data that support the findings of this study are available on request from the corresponding author [MY]. The data are not publicly available because they contain information that could compromise research participants' privacy/consent.

\section{Declarations}

\section{Ethics approval and consent to participate}

This study was approved by the Ethics Committee of the Faculty of Social and Behavioral Sciences of Utrecht University and filed under number FETC17-132 (Helbich-Yang-Geo).

The informed consent was obtained from all subjects.

The authors declare that all methods were carried out in accordance with relevant guidelines and regulations.

\section{Consent for publication}

Not applicable.

\section{Competing interests}

We declare no competing interests.

\section{Author details}

'Department of Human Geography and Spatial Planning, Faculty of Geosciences, Utrecht University, Princetonlaan 8A, Utrecht, CB 3584, The Netherlands. ${ }^{2}$ LISER, Luxembourg Institute of Socio-Economic Research, Esch-sur-Alzette, Luxembourg. ${ }^{3}$ University of Luxembourg, Esch-sur-Alzette, Luxembourg.

\section{Received: 5 March 2021 Accepted: 9 June 2021}

\section{Published online: 28 June 2021}

\section{References}

1. Knoema. Urban population as a share of total population (\%) (2019). knoema.com. 2019. https://knoema.com/atlas/China/Urban-popula tion?origin=cn.knoema.com. Accessed 25 Feb 2020.

2. Xu J, Wang J, Wimo A, Qiu C. The economic burden of mental disorders in China, 2005-2013: implications for health policy. BMC Psychiatry. 2016;16(1): 137. https://doi.org/10.1186/s12888-016-0839-0.

3. Li J, Rose N. Urban social exclusion and mental health of China's rural-urban migrants - A review and call for research. Health Place. 2017;48:20-30. https://doi.org/10.1016/i.healthplace.2017.08.009.

4. Li X, Stanton B, Fang X, Lin D. Social stigma and mental health among ruralto-urban migrants in China: A conceptual framework and future research needs. World Health Popul. 2006;8:14-31. https://doi.org/10.12927/whp.2 006.18282

5. Wong DFK, He X, Leung G, Lau Y, Chang Y. Mental health of migrant workers in China: prevalence and correlates. Soc Psychiatry Psychiatr Epidemiol. 2008;43(6):483-9. https://doi.org/10.1007/s00127-008-0341-1.

6. Chen Y, Chen H, Liu J. Household split, income, and migrants' life satisfaction: Social problems caused by rapid urbanization in China. Sustain. 2019;11. https://doi.org/10.3390/su10023415.

7. Hu X, Cook S, Salazar MA. Internal migration and health in China. Lancet. 2008;372(9651):1717-9. https://doi.org/10.1016/S0140-6736(08)61360-4.

8. Wang B, Li X, Stanton B, Fang X. The influence of social stigma and discriminatory experience on psychological distress and quality of life among rural-to-urban migrants in China. Soc Sci Med. 2010;71(1):84-92. https://doi.org/10.1016/j.socscimed.2010.03.021.

9. Zhang CJP, Lai P, Barnett A, Sit CHP, Lee RSY, Cerin E, et al. To what extent does physical activity explain the associations between neighborhood environment and depressive symptoms in older adults living in an Asian metropolis? Ment Health Phys Act. 2018; November:0-1. https://doi.org/10.1 016/j.mhpa.2018.11.005.

10. Yang M, Dijst M, Helbich M. Mental health among migrants in Shenzhen, China: does it matter whether the migrant population is identified by hukou or birthplace? Int J Environ Res Public Health. 2018;15(12):2671. https://doi.org/10.3390/ijerph15122671.

11. Diez Roux AV, Mair C. Neighborhoods and health. Ann N Y Acad Sci. 2010; 1186(1):125-45. https://doi.org/10.1111/j.1749-6632.2009.05333.x.

12. Helbich M, Hagenauer J, Roberts $\mathrm{H}$. Relative importance of perceived physical and social neighborhood characteristics for depression: a machine learning approach. Soc Psychiatry Psychiatr Epidemiol. 2020;55(5):599-610. https://doi.org/10.1007/s00127-019-01808-5.

13. Ma J, Li C, Kwan MP, Chai Y. A multilevel analysis of perceived noise pollution, geographic contexts and mental health in Beijing. Int J Environ Res Public Health. 2018:15:1-18.

14. Dzhambov AM, Markevych I, Tilov B, Arabadzhiev Z, Stoyanov D, Gatseva P, et al. Pathways linking residential noise and air pollution to mental ill-health in young adults. Environ Res. 2018;166:458-65. https://doi.org/10.1016/j. envres.2018.06.031.

15. Bird C. A brief introduction to the built environment and health. Perspect Public Health. 2012;132:105.

16. Wang R, Liu Y, Xue D, Helbich M. Depressive symptoms among Chinese residents: how are the natural, built, and social environments correlated? BMC Public Health. 2019;19:1-8.

17. Li J, Liu Z. Housing stress and mental health of migrant populations in urban China. Cities. 2018, 2017:1-8. https://doi.org/10.1016/j.cities.2018.04. 006.

18. Liu Y, Wang R, Grekousis G, Liu Y, Yuan Y, Li Z. Neighbourhood greenness and mental wellbeing in Guangzhou, China: What are the pathways? Landsc Urban Plan. 2019;190:1-9. https://doi.org/10.1016/j.landurbplan.201 9.103602.

19. Helbich M. Toward dynamic urban environmental exposure assessments in mental health research. Environ Res. 2018, 161 (2017):129-35. https://doi. org/10.1016/j.envres.2017.11.006.

20. Dawson CT, Wu W, Fennie KP, Ibañez G, Cano M, Pettit JW, et al. Perceived neighborhood social cohesion moderates the relationship between neighborhood structural disadvantage and adolescent depressive symptoms. Health Place. 2019, 56(2018):88-98. https://doi.org/10.1016/.jhea Ithplace.2019.01.001.

21. Liu Y, Zhang F, Liu Y, Li Z, Wu F. The effect of neighbourhood social ties on migrants' subjective wellbeing in Chinese cities. Habitat Int. 2017;66:86-94. https://doi.org/10.1016/j.habitatint.2017.05.011.

22. Wang R, Liu Y, Xue D, Yao Y, Liu P, Helbich M. Cross-sectional associations between long-term exposure to particulate matter and depression in China: the mediating effects of sunlight, physical activity, and neighborly reciprocity. J Affect Disord. 2019;249:8-14. https://doi.org/10.1016/j.jad.2019.02.007.

23. Barr PB. Early neighborhood conditions and trajectories of depressive symptoms across adolescence and into adulthood. Adv Life Course Res. 2018, 35(2017):57-68. https://doi.org/10.1016/j.alcr.2018.01.005.

24. Cherrie MPC, Shortt NK, Mitchell RJ, Taylor AM, Redmond P, Thompson CW, et al. Green space and cognitive ageing: a retrospective life course analysis in the Lothian birth cohort 1936. Soc Sci Med. 2018;196(2017):56-65. https://doi.org/10.1016/j.socscimed.2017.10.038.

25. Jivraj S, Norman P, Nicholas O, Murray ET. Are there sensitive neighbourhood effect periods during the life course on midlife health and wellbeing? Health Place. 2019;57(2018):147-56. https://doi.org/10.1016/j.hea Ithplace.2019.03.009

26. Coulter R, van Ham M, Findlay AM. Re-thinking residential mobility: linking lives through time and space. Prog Hum Geogr. 2015;40:352-74.

27. Pearce J, Cherrie M, Shortt N, Deary I. Life course of place: a longitudinal study of mental health and place. Trans Inst Br Geogr. 2018;43(4):555-72. https://doi.org/10.1111/tran.12246.

28. Brazil N, Clark WAV. Individual mental health, life course events and dynamic neighbourhood change during the transition to adulthood. Health Place. 2017;45(2016):99-109.

29. Chen J, Chen S, Landry PF. Urbanization and mental health in China: linking the 2010 population census with a cross-sectional survey. Int J Environ Res Public Health. 2015;12(8):9012-24. https://doi.org/10.3390/ijerph120809012.

30. Dong H, Qin B. Exploring the link between neighborhood environment and mental wellbeing: a case study in Beijing, China. Landsc Urban Plan. 2017; 164(2016):71-80. https://doi.org/10.1016/j.landurbplan.2017.04.005. 
31. Ruijsbroek A, Mohnen SM, Droomers M, Kruize H, Gidlow C, Gražulevičiene $R$, et al. Neighbourhood green space, social environment and mental health: an examination in four European cities. Int J Public Health. 2017; 62(6):657-67. https://doi.org/10.1007/s00038-017-0963-8.

32. Rautio N, Filatova S, Lehtiniemi H, Miettunen J. Living environment and its relationship to depressive mood: a systematic review. Int J Soc Psychiatry. 2018;64(1):92-103. https://doi.org/10.1177/0020764017744582.

33. Breiman L. Random forests. Mach Learn. 2001;45(1):5-32. https://doi.org/10.1 023/A:1010933404324.

34. Shenzhen Municipal Bureau of Statistics. Statistical report of Shenzhen population 2016. 2018. http://www.sztj.gov.cn/xxgk/zfxxgkml/tjsj/tjgb/201 804/t20180427_11800902.htm. Accessed 9 Dec 2018.

35. Li SM, Zhu Y, Li L. Neighborhood type, gatedness, and residential experiences in Chinese cities: a study of Guangzhou. Urban Geogr. 2012; 33(2):237-55. https://doi.org/10.2747/0272-3638.33.2.237.

36. Ye S. Factor structure of the general health questionnaire (GHQ-12): the role of wording effects. Personal Individ Differ. 2009;46(2):197-201. https://doi. org/10.1016/j.paid.2008.09.027.

37. Goldberg DP, Oldehinkel T, Ormel J. Why GHQ threshold varies from one place to another. Psychol Med. 1998;28:S0033291798006874(4):915-21. https://doi.org/10.1017/S0033291798006874

38. Wang $Z$, Lee $C$. Site and neighborhood environments for walking among older adults. Health Place. 2010;16(6):1268-79. https://doi.org/10.1016/j.hea Ithplace.2010.08.015.

39. Osypuk TL, Kehm R, Misra DP. Where we used to live: validating retrospective measures of childhood neighborhood context for life course epidemiologic studies. PLoS One. 2015;10(4):e0124635. https://doi.org/10.13 71/journal.pone.0124635.

40. Cerin E, Saelens BE, Sallis JF, Frank LD. Neighborhood environment walkability scale: validity and development of a short form. Med Sci Sports Exerc. 2006;38(9):1682-91. https://doi.org/10.1249/01.mss.0000227639.83 $607.4 d$.

41. Roberts JM, Stephen W. Neighborhoods and violent crime : a multilevel study of collective efficacy, vol. 277; 2012. p. 1-21.

42. Huang X, Dijst M, Weesep J, Jiao Y, Sun Y. Residential choice among ruralurban migrants after Hukou reform: evidence from Suzhou, China. Popul Space Place. 2017;23:1-18.

43. Scott D, Happell B. The high prevalence of poor physical health and unhealthy lifestyle behaviours in individuals with severe mental illness. Issues Ment Health Nurs. 2011;32(9):589-97. https://doi.org/10.3109/0161284 0.2011 .569846

44. Lu Y, Qin L. Healthy migrant and salmon bias hypotheses: a study of health and internal migration in China. Soc Sci Med. 2014;102:41-8. https://doi. org/10.1016/j.socscimed.2013.11.040.

45. Fernández-Delgado M, Cernadas E, Barro S, et al. Do we need hundreds of classifiers to solve real world classification problems? J Mach LearnRes. 2014; 15:3133-81. https://doi.org/10.1117/1.JRS.11.015020.

46. Hagenauer J, Omrani $H$, Helbich M. Assessing the performance of 38 machine learning models: the case of land consumption rates in Bavaria, Germany. Int J Geogr Inf Sci. 2019;33(7):1399-419. https://doi.org/10.1080/13 658816.2019 .1579333$.

47. James G, Witten D, Hastie T, Tibshirani R. Tree-based methods. In: An introduction to statistical learning, springer texts. 8th ed. New York: Springer Texts in Statistics; 2013. p. 303-37. https://doi.org/10.1007/978-1-4614-7138-7_8.

48. Fox EW, Hill RA, Leibowitz SG, et al. Assessing the accuracy and stability of variable selection methods for random forest modeling in ecology. Environ Monit Assess. 2017;189. https://doi.org/10.1007/s10661-017-6025-0.

49. Ishwaran $\mathrm{H}$. The effect of splitting on random forests. Mach Learn. 2015; 99(1):75-118. https://doi.org/10.1007/s10994-014-5451-2.

50. Goldstein A, Kapelner A, Bleich J, Pitkin E. Peeking inside the black box: visualizing statistical learning with plots of individual conditional expectation. J Comput Graph Stat. 2015;24(1):44-65. https://doi.org/10.1 080/10618600.2014.907095

51. Friedman JH, Popescu BE. Predictive learning via rule ensembles. Ann Appl Stat. 2008;2:916-54. https://doi.org/10.1214/07-AOAS148.

52. Molnar C. Interpretable machine learning. In: A Guide for Making Black Box Models Explainable. Book; 2019.

53. R Development Core Team R. R: A Language and Environment for Statistical Computing. 2011.

54. Wright MN, Ziegler A. Ranger: A fast implementation of random forests for high dimensional data in C++ and R. J Stat Softw; 2017.
55. Zheng S, Long F, Fan CC, Gu Y. Urban villages in China: a 2008 survey of migrant settlements in Beijing. Eurasian Geogr Econ. 2009;50(4):425-46. https://doi.org/10.2747/1539-7216.50.4.425.

56. Sun L. Housing affordability in Chinese cities; 2020.

57. Cui C, Geertman S, Hooimeijer P. Access to homeownership in urban China: a comparison between skilled migrants and skilled locals in Nanjing. Cities. 2016:50:188-96. https://doi.org/10.1016/j.cities.2015.10.008.

58. Sun M, Fan CC. China's permanent and temporary migrants: differentials and changes, 1990-2000. Prof Geogr. 2011;63(1):92-112. https://doi.org/10.1 080/00330124.2010.533562

59. Tao Y, Yuan Y. Annual Report on the Development of China's Special Economic Zones(2018): Blue Book of China's Special Economic Zones: Springer Singapore; 2019. https://books.google.nl/books?id=UOK_DwAAQBA J.

60. Gao M, Ahern J, Koshland CP. Perceived built environment and healthrelated quality of life in four types of neighborhoods in Xi'an, China. Health Place. 2016;39:110-5. https://doi.org/10.1016/j.healthplace.2016.03.008.

61. Markevych I, Schoierer J, Hartig T, Chudnovsky A, Hystad P, Dzhambov AM, et al. Exploring pathways linking greenspace to health: Theoretical and methodological guidance. Environ Res. 2017;158:301-17. https://doi.org/10.1 016/j.envres.2017.06.028

62. Huang X, Dijst M, van Weesep J, Zou N, Cui C, Geertman S, et al. Residential mobility in China: home ownership among rural-urban migrants after reform of the hukou registration system. J Housing Built Environ. 2014;29(4): 615-36. https://doi.org/10.1007/s10901-013-9370-5.

63. Maas R, Kloeckner CA, Lindstrøm B, Lillefjell M. The impact of neighborhood social capital on life satisfaction and self-rated health: A possible pathway for health promotion? Health Place. 2016;42:120-8. https://doi.org/10.1016/j. healthplace.2016.09.011.

64. O'Campo P, Salmon C, Burke J. Neighbourhoods and mental well-being: what are the pathways? Health Place. 2009;15(1):56-68. https://doi.org/10.1 016/j.healthplace.2008.02.004.

65. Matheson Fl, Moineddin R, Dunn JR, Creatore MI, Gozdyra P, Glazier RH. Urban neighborhoods, chronic stress, gender and depression. Soc Sci Med. 2006;63(10):2604-16. https://doi.org/10.1016/j.socscimed.2006.07.001.

66. Kubzansky LD, Subramanian SV, Kawachi I, Fay ME, Soobader MJ, Berkman LF. Neighborhood contextual influences on depressive symptoms in the elderly. Am J Epidemiol. 2005;162(3):253-60. https://doi.org/10.1093/aje/kwi185.

67. O'Campo P, Wheaton B, Nisenbaum R, Glazier RH, Dunn JR, Chambers C. The Neighbourhood effects on health and well-being (NEHW) study. Health Place. 2015;31:65-74. https://doi.org/10.1016/j.healthplace.2014.11.001.

68. Wen M, Fan J, Jin L, Wang G. Neighborhood effects on health among migrants and natives in Shanghai, China. Health Place. 2010;16(3):452-60. https://doi.org/10.1016/j.healthplace.2009.12.001.

69. Tunstall H, Mitchell R, Pearce J, Shortt N. The general and mental health of movers to more- and less-disadvantaged socio-economic and physical environments within the UK. Soc Sci Med. 2014;118(C):97-107. https://doi. org/10.1016/j.socscimed.2014.07.038.

70. Humpel N, Owen N, Leslie E. Environmental factors associated with adults' participation in physical activity. A review. Am J Prev Med. 2002;22(3):18899. https://doi.org/10.1016/S0749-3797(01)00426-3.

71. Renalds A, Smith TH, Hale PJ. A systematic review of built environment and health.Pdf. Fam Community Health. 2010;33(1):68-78. https://doi.org/10.1 097/FCH.0b013e3181c4e2e5.

72. Tan Y, Li L, Ren Y, Kawachi I, Su M, LV J, et al. Association between perceived urban built environment attributes and leisure-time physical activity among adults in Hangzhou, China. Prev Med (Baltim). 2014;66:60-4. https://doi.org/10.1016/j.ypmed.2014.06.001.

73. Gong Y, Palmer S, Gallacher J, Marsden T, Fone D. A systematic review of the relationship between objective measurements of the urban environment and psychological distress. Environ Int. 2016;96:48-57. https:// doi.org/10.1016/j.envint.2016.08.019.

74. Beard JR, Tracy M, Vlahov D, et al. Trajectory and Socioeconomic Predictors of Depression in a Prospective Study of Residents of New York City. Ann Epidemiol. 2008;18:235-43. https://doi.org/10.1016/j.annepidem.2007.10.004.

75. Weden MM, Carpiano RM, Robert SA. Subjective and objective neighborhood characteristics and adult health. Soc Sci Med. 2008;66(6): 1256-70. https://doi.org/10.1016/j.socscimed.2007.11.041.

76. Gu D, Zhu H, Wen M. Neighborhood-health links: differences between ruralto-urban migrants and natives in Shanghai. Demogr Res. 2015:33:499-524. https://doi.org/10.4054/DemRes.2015.33.17. 
77. Ohrnberger J, Fichera E, Sutton M. The relationship between physical and mental health: A mediation analysis. Soc Sci Med. 2017;195:42-9. https://doi. org/10.1016/j.socscimed.2017.11.008.

78. Meyer OL, Castro-Schilo L, Aguilar-Gaxiola S. Determinants of mental health and self-rated health: a model of socioeconomic status, neighborhood safety, and physical activity. Am J Public Health. 2014;104(9):1734-41. https://doi.org/10.2105/A.JPH.2014.302003.

79. Wen M, Hawkley LC, Cacioppo JT. Objective and perceived neighborhood environment, individual SES and psychosocial factors, and self-rated health: an analysis of older adults in Cook County, Illinois. Soc Sci Med. 2006;63(10): 2575-90. https://doi.org/10.1016/.socscimed.2006.06.025.

80. Roh S, Jang Y, Chiriboga DA, Kwag KH, Cho S, Bernstein K. Perceived neighborhood environment affecting physical and mental health: a study with Korean American older adults in new York City. J Immigr Minor Health. 2011:13(6):1005-12. https://doi.org/10.1007/s10903-011-9492-3.

81. Gresenz CR, Sturm R, Tang L. Income and mental health: unraveling community and individual level relationships. J Ment Health Policy Econ. 2001;4(4):197-203.

82. Ohrnberger J, Fichera E, Sutton M. The dynamics of physical and mental health in the older population. J Econ Ageing. 2017;9:52-62. https://doi. org/10.1016/j.jeoa.2016.07.002.

83. Qiu P, Caine E, Yang Y, Chen Q, Li J, Ma X. Depression and associated factors in internal migrant workers in China. J Affect Disord. 2011;134(1-3): 198-207. https://doi.org/10.1016/j.jad.2011.05.043.

84. Gong P, Liang S, Carlton EJ, Jiang Q, Wu J, Wang L, et al. Urbanisation and health in China. Lancet. 2012;379(9818):843-52. https://doi.org/10.1016/S014 0-6736(11)61878-3.

85. Lam KKF, Johnston JM. Health insurance and healthcare utilisation for Shenzhen residents: a tale of registrants and migrants? BMC Public Health. 2012;12(1):1. https://doi.org/10.1186/1471-2458-12-868.

86. Zhang L, Zhou S, Kwan M. A comparative analysis of the impacts of objective versus subjective neighborhood environment on physical , mental , and social health. Health Place. 2019;59:102170. https://doi.org/10.1016/j. healthplace.2019.102170

\section{Publisher's Note}

Springer Nature remains neutral with regard to jurisdictional claims in published maps and institutional affiliations.

Ready to submit your research? Choose BMC and benefit from:

- fast, convenient online submission

- thorough peer review by experienced researchers in your field

- rapid publication on acceptance

- support for research data, including large and complex data types

- gold Open Access which fosters wider collaboration and increased citations

- maximum visibility for your research: over $100 \mathrm{M}$ website views per year

At $\mathrm{BMC}$, research is always in progress.

Learn more biomedcentral.com/submissions 